\title{
O PROCESSO DE LUTO NO IDOSO PELA MORTE DE CÔNJUGE E FILHO
}

\author{
João Batista Alves de Oliveira* \\ Ruth Gelehrter da Costa Lopes ${ }^{\#}$
}

RESUMO. Este artigo tem por finalidade discutir a importância de se entender e acompanhar o processo de luto na velhice, principalmente no caso de morte do cônjuge ou filho, que pode provocar um grande impacto no idoso, com repercussões físicas e emocionais, que acrescem a vários outros sofrimentos desta faixa etária, renegada pela sociedade atual.

Palavras-chave: luto, velhice, psicogerontologia.

\section{THE MOURNING PROCESS IN THE ELDERLY AT THE DEATH OF SPOUSE OR CHILDREN}

\begin{abstract}
The importance of understanding and following up the mourning process in the elderly, mainly when it refers to the spouses and children's death, is discussed. The event is a great impact on the elderly and affects them physically and emotionally. This is linked to other sufferings typical of their advanced age whose comprehension is frequently denied by current society.
\end{abstract}

Key words: Mourning, the aged, psychogerontology.

\section{EL PROCESO DE DUELO EN EL ANCIANO POR LA MUERTE DE LA PAREJA Y DE HIJO}

RESUMEN. Este artículo tiene por meta deliberar sobre la importancia de entender y acompañar el proceso de duelo en la vejez, sobretodo por la muerte de la pareja e hijo que pude provocar un gran impacto en el anciano con manifestaciones físicas y emocionales que se juntan a diversos otros sufrimientos en esta fase rechazada por la sociedad actual.

Palabras-clave: Duelo, vejez, psicogerontología.

A sociedade moderna, pautada no produtivismo e consumismo, adota o jovem como seu modelo essencial, e conseqüentemente estigmatiza a velhice, cuja consideração é algo feito genericamente, quando então só o outro envelhece, não afetando a individualidade.

Renegar a velhice está ligado à não-aceitação de corpos que evidenciam a marca dos anos, os quais são o oposto do idealizado padrão jovem no modelo social atual, talvez porque a velhice é a fase que mais se aproxima da morte. Sua consideração leva ao reconhecimento das próprias restrições e da finitude: "quanto ao desenvolvimento chegamos a uma fase conhecida como velhice que, como vimos, não tem início definido, mas cujo fim é claramente a morte" (Kovács, 2002, p. 8).

A morte, neste modelo social, é algo relegado a um segundo plano, a não ser discutido, como se isso pudesse evitá-la. É aquela interdita, que deve ser escondida, institucionalizada, medicalizada, sem grandes demonstrações de dor pelos enlutados, não mais portadora de ritos.

Em decorrência desse modelo o luto deixou de ser valorizado, fato que repercute no meio acadêmico pela ausência significativa de estudos referentes à temática, cujo resgate se faz necessário, principalmente na atualidade, quando discutimos e vivemos a longevidade e os Cuidados Paliativos.

Médico. Mestre em Gerontologia.

* Doutora em Saúde Pública. Vice-Coordenadora do Programa de Pós-Graduação em Gerontologia na Pontifícia Universidade Católica de São Paulo - PUC-SP. 


\section{O PROCESSO DE LUTO}

Luto pode ser definido como um conjunto de reações diante de uma perda, portanto algo a não ser desprezado, e sim, devidamente valorizado e acompanhado, como parte da saúde emocional. O luto é "afinal o acontecimento vital mais grave que a maior parte de nós pode experienciar" (Parkes, 1998, p. 44). Sua dor "é tanto parte da vida quanto a alegria de viver; é talvez, o preço que pagamos pelo amor, o preço do compromisso" (Parkes, 1998, p. 22). Não obstante, cumpre considerar que o luto "não é um conjunto de sintomas que tem início após uma perda e, depois gradualmente se desvanece. Envolve uma sucessão de quadros clínicos que se mesclam e se substituem" (Parkes, 1998, p. 23). Podemos tomar como conceito bem adequado o de que "o luto é um processo de aperceber-se, de tornar real o fato da perda" (Parkes, 1998, p. 199).

Desde milênios vemos presentes os rituais, os quais sempre tiveram a finalidade de servir como uma forma de proteção no conflito vida $\mathrm{x}$ morte.

Podemos ver no luto vários simbolismos, um dos quais é a cor. Para algumas sociedades, o branco, o amarelo e o violeta caracterizam a fase; para outras, como a nossa, é o preto que facilita o reconhecimento da perda. Outro simbolismo clássico em nossa sociedade predominantemente católica é o ato religioso, mais comumente representado pela missa de corpo presente e a de sétimo dia.

O luto é a fase da expressão dos sentimentos decorrentes da perda, a qual se demonstra por choque, desejo, desorganização e organização; é a fase de aprender que a morte deve ser tornada real, a partir do que se torna possível estabelecer novas concepções sobre o mundo, favorecendo investimentos pessoais.

A fase do choque pode durar horas ou dias, constituindo-se de desespero, raiva, irritabilidade, amargura e isolamento. Tais sentimentos podem se manifestar por atitudes emocionais intensas e passam a ser expressos contra todo aquele que venha a compartilhar o luto, como uma manifestação de defesa, pois a aceitação desses sentimentos reafirma a perda.

A fase do desejo é caracterizada por um forte impulso de busca pela figura perdida. Nela ocorre um estado de vigília, de movimentação para os locais onde a pessoa normalmente estaria, e mesmo de chamamento, como formas de descaracterizar a perda, pois se ela é procurada, ela não morreu. Essa fase pode durar anos ou meses, sendo comuns os desapontamentos por sua não-efetividade, com episódios de choro e de tristeza quando da constatação da sua inutilidade.

Nesta fase da busca e do desejo se misturam a desorganização e o desespero, pois esta perda traz consigo outras secundárias, cuja intensidade dependerá das características da personalidade e das experiências prévias do enlutado e do apoio recebido por parte da sociedade e da família.

A fase de reorganização, quando há reapropriação de parte da energia do investimento objetal ao ego, caracteriza-se pela aceitação da perda definitiva e pela conseqüente constatação de que uma nova vida precisa ser iniciada. No entanto, é possível ocorrer recidiva de episódios de saudade e de tristeza.

Uma forma de abrandar o luto é manter a sensação de que a pessoa está por perto e criar uma idealização através do reviver de lembranças felizes. Podem ser, neste caso, bem-vindos os tributos ao falecido, pois isto representa que este é merecedor da dor dos sobreviventes.

O luto, como não é um processo linear, não tem data para terminar, podendo durar meses e anos, ou mesmo nunca acabar, na dependência direta das características individuais da personalidade e ainda do nível e intensidade de relação que se manteve com o falecido.

Não há uma clara e estática definição para os tipos de luto. Normalmente ele é considerado patológico quando é por demais prolongado $\mathrm{e}$ apresenta características obsessivas.

No luto bem-elaborado, gradualmente tem-se o desinvestimento, da libido objetal e reapropriação da libido egóica, o que, no entanto, não ocorre na melancolia, pois o objeto não pode ser renunciado e o investimento objetal continua e pode até ser mais intenso, não permitindo então a retirada dessa energia para ser reapropriada ao ego. No luto mal-elaborado podem surgir os quadros melancólicos: enquanto o luto representa a perda real, a melancolia representa o inconsciente, relacionado ao objeto perdido, quando não se sabe verdadeiramente o que se perdeu.

O processo de luto mostra-se organizado e é conscientemente aceito quando a morte foi tomada como real e o enlutado apresenta disponibilidade para novos investimentos em sua vida, podendo assim manter vivos os sentimentos em relação ao falecido, a que se alia a recuperação da auto-estima e da valorização do ego.

\section{AS REPERCUSSÕES DO LUTO NO IDOSO}

O luto pode representar um processo de grande impacto no idoso, pois este traz consigo perdas 
pessoais e sociais decorrentes de a velhice ser estigmatizada como fase da invalidez ou da condescendência. Por isso, devemos considerar que trabalhar emocionalmente as perdas decorrentes de alterações físicas e isolamento social é complicado, e pior se associadas à morte do cônjuge e, principalmente, de um filho.

Os ritos de morte e de luto, importantes para o psiquismo, vêm sendo desconsiderados ou realizados rapidamente; porém, "para que a morte de um ente querido não assuma formas obsessivas no inconsciente é necessário ritualizar essa passagem" (Brasil Escola, s/d). A desconsideração formal ocorre tanto por parte da sociedade como da própria família, o que requer uma mudança de atitude do meio acadêmico, para que se traga à discussão o tema e então se possa efetivamente cuidar do enlutado, principalmente o idoso, desconsiderado em suas múltiplas necessidades, principalmente as emocionais.

Durante o processo de luto é importante avaliar que tipo de ajuda se faz necessária. É importante permitir a ritualidade do processo, que pode ser diferente entre culturas e pessoas, não sendo possível estipular um padrão de comportamento. A ajuda pode surgir de diferentes áreas, como a profissional, a leiga e, principalmente, a religiosa.

O idoso deve ser acompanhado e deve-lhe ser permitido tempo para reorganizar-se emocionalmente. $\mathrm{Na}$ fase inicial do luto ele pode ter necessidade de ajuda para atividades básicas da vida diária, pois "a máscara usada no funeral não pode mais ser mantida e é necessário que algum parente ou amigo próximo assuma muitos dos papéis e responsabilidades do enlutado, deixando-o livre para vivenciar o luto" (Parkes, 1998, p. 205)

A expressão emocional deve ser permitida abertamente, não se considerando a necessidade de medicalizar o fato. $\mathrm{O}$ enlutado deve ser livre para expressar seus sentimentos de raiva e angústia, que comumente ocorrerão para com aqueles que o ajudam, pois são os que mais estarão reafirmando a perda.

Importante considerar que "o enlutado tem uma tarefa dolorosa e difícil para realizar, que não pode ser evitada nem apressada. A verdadeira ajuda consiste em reconhecer o fato e permitir que ele se organize para que fique disponível para elaborar a perda" (Parkes, 1998, p. 205).

No idoso em processo de luto podem ocorrer alguns distúrbios, como os do sono e da alimentação, ou ainda manifestações somáticas, sendo comum falta de ar, aperto no peito, falta de energia, insônia, passividade, alucinações e ansiedade.
As alterações do sono podem estar relacionadas à somatização ou dever-se ao fato de que "durante o sono ou em períodos de atenção relaxada, as lembranças dolorosas tendem a invadir nossa mente e nos pegamos revivendo o trauma mais uma vez" (Parkes, 1998, p. 59).

Há os casos de "morte natural precoce" nos idosos, que se relacionam com o rebaixamento da auto-estima e com o empobrecimento do ego; porém devemos considerar que "o fato do luto levar à morte por doenças cardíacas não prova que ele seja, isoladamente, uma causa de morte. Nem sequer sabemos se o luto provoca doença ou agrava uma condição que, mais cedo ou mais tarde, se manifestaria" (Parkes, 1998, p. 34).

Um idoso pode conviver por tempo prolongado com seu cônjuge portador de doença crônica e incapacitante, tornando o luto antecipatório uma realidade na velhice; no entanto isto "não significa que esse possa ser sempre completo, pois mesmo que as pessoas se preparem, sempre há coisas que não podem ser antecipadas" (Parkes, 1998, p. 196).

Durante essa fase podem aparecer sentimentos ambivalentes no cuidador: o desejo de que o outro sobreviva e ao mesmo tempo o da morte para acabar com o sofrimento. Isto desperta o sentimento de culpa, pois de qualquer forma se está desejando algo que não é bom para aquele que se ama e que está sofrendo.

Devemos considerar o impacto da morte de um filho no idoso como capaz de suscitar o sentimento de culpa por estar sobrevivendo ao filho, agravado pela dificuldade em trabalhar emocionalmente a morte, somada a tantas outras presentes, decorrentes de alterações físicas e isolamento social.

Remetendo-nos a Freud, podemos analisar o significado da perda de um filho quando esse autor diz que "a perda de um filho parece produzir uma grave ferida narcísica" (Goldfarb, 2002).

Esta afirmação pode ser interpretada de duas formas: a primeira é como o reconhecimento de que o investimento libidinal que fizera no outro (sua filha Sophie e seu neto Heinelle) fora reflexo do investimento em si mesmo, através do outro; a segunda é a sanidade ao reconhecer que essa libido egóica projetada no objeto necessita ser reapropriada ao ego. A ferida narcísica representa o reconhecimento de que uma parte de si, investida no outro através da libido objetal, perdeu-se com a morte do objeto; uma parte de si, satisfeita pelo investimento no filho (narcisismo dos pais), que morre junto.

Encarar a morte como parte da vida é algo rejeitado pela consciência. Nossa libido é centrada na construção da vida, portanto há pouco lugar para a 
morte, que representa o limite, dor, sofrimento e o fim: "A morte estabelece um exílio em relação às pessoas que se ama e que carregam consigo sonhos e esperanças" (Rezende, 2000, p. 15).

Lidar com a morte é mais difícil quando se conviveu com a pessoa. Imaginemos quão mais intenso é o luto para aqueles que não só conviveram com o falecido,, mas também foram seus progenitores.

Para Raimbault (citado por Kovács, 2002), a fim de que se realize o processo de luto é necessário:

1. uma desidentificação e um desligamento do sentimento em relação ao morto; 2. a aceitação da inevitabilidade da morte; 3 . quando for possível, encontrar um substituto para a libido desinvestida (p. 155).

Agora imaginemos quão difícil é para os pais desidentificar e desligar seus sentimentos em relação ao filho e quanto talvez possa ser impossível se ter um substituto para a libido investida.

Não bastasse ser complicado naturalmente, temos ainda que considerar as características emocionais e da personalidade de cada indivíduo envolvido.

No processo de luto, quanto maior o investimento afetivo objetal, maior será a energia para o desligamento. Imaginemos então quanta energia será necessária para os pais se desligarem do filho (se é que é possível).

Não é raro ocorrer reações de agressividade contra a figura perdida, funcionando como um mecanismo de defesa, pois com a desvalorização do objeto fica mais fácil reconciliar o ego ferido com o ideal abalado, favorecendo a reapropriação ao ego de parte dessa energia objetal.

A morte de um filho pode representar a impotência do amor dos pais para evitar esse evento final, podendo colocar em dúvida a qualidade desse amor, como se esse tivesse fracassado. Eles podem sentir-se culpados por sobreviverem ao filho.

$\mathrm{Na}$ ocorrência da morte abrupta, ocorre uma ruptura brusca no investimento objetal, emergindo a pulsão de morte, que é uma categoria fundamental das pulsões que se contrapõem à de vida, tendendo à autodestruição (Laplanche \& Pontalis, 2004). Esta pode ser ainda maior quando a morte foi violenta, com mutilação do corpo, e principalmente quando ocorreu por suicídio, suscitando um forte sentimento de culpa, fracasso e impotência.

Não é raro ocorrer nesses pais a reação de aniversário, ou seja, numa data - a da morte ou do aniversário - viverem momentos de sofrimento psíquico ou mesmo somático. Podem ocorrer sintomas de pânico, boca seca e outras indicações da atividade do sistema nervoso autônomo relacionadas ao período de dor. Alguns podem apresentar ideação suicida (Parkes, 1998, p. 63).

Refúgio no alcoolismo pode ser uma saída para aqueles que bebiam e apresentavam um ajustamento psíquico precário. No idoso é comum surgir quadro depressivo, o qual pode manifestar-se com sintomatologias das mais variadas, porém sempre presentes o desânimo e a perda da capacidade de amar, decorrentes do processo de culpa. O traço mais característico do luto não é a depressão profunda, mas sim, episódios agudos de dor, com muita saudade e dor psíquica (Parkes, 1998, p. 62).

$\mathrm{O}$ idoso pode ter dificuldades para vivenciar o processo de luto por vários motivos, sendo um deles a inabilidade em falar sobre a dor relacionada à perda, pois na sociedade atual as pessoas "preferem afastarse do medo da morte, levando a um recalcamento da perda, em lugar de manifestações outrora usuais" (Brasil Escola, s/d). A velhice, que normalmente é reconhecida como a fase da sabedoria e do amadurecimento, o que favoreceria melhor essa vivência, ao contrário, se apresenta como a fase de pouca disponibilidade para a elaboração da perda, ou mesmo como aquela em que faltam condições emocionais próprias e principalmente as advindas do entrosamento com o outro vivo, muito mais importantes do que as oriundas do relacionamento com o falecido. Falta, nesse momento, uma relação mais íntima, seja terapêutica seja de amizade, para uma ajuda eficaz. Isso exige um compartilhar de sentimentos, que não é facilmente conseguido. Talvez neste contexto possamos entender a afirmação de que "na maioria das vezes os enlutados vivenciam a dor da perda na solidão" (Brasil Escola, s/d), pois o enfrentamento da dor e do luto ocorre sem condições resolutivas, já que estes são desconsiderados os vários fatores pessoais, familiares e sociais que comumente favorecem alterações emocionais no idoso.

$\mathrm{Na}$ atualidade há que se reverter essa situação, com o incentivo aos profissionais a lidarem com as repercussões da morte e do luto nesse indivíduo que, depois de anos vividos, pode não mais suportar perdas, pois "o equilíbrio psíquico do idoso depende, basicamente, de sua capacidade de adaptação à sua existência presente e passada e das condições da realidade que o cercam" (Ballone, $\mathrm{s} / \mathrm{d}$ ).

Pensar que é mais fácil hoje a vivência desse processo, em decorrência da assistência profissional, pode não corresponder à realidade, afinal, no luto não há o que se tratar; há que se estar junto.

Devemos então considerar que cada um viverá essa morte do cônjuge ou filho de acordo com o 
histórico de convivência entre esses e com as características da personalidade e dos mecanismos de defesa psicológica dos sobreviventes, pois "para cada enlutado, sua perda é a pior, a mais difícil, pois cada pessoa é aquela que sabe dimensionar sua dor e seus recursos para enfrentá-la" (Brasil Escola, s/d). A partir disto é preciso estarmos profissionalmente preparados para intervir nos casos necessários, e sem nos basear em um tempo cronológico, mas sim, nas repercussões para a vida do idoso. Não sendo o luto patológico, independentemente do tempo, somente haveremos de intervir se a necessidade de ajuda partir da própria pessoa, quando não se sente capaz de superar sozinha esta fase.

Nos casos de luto patológico o enlutado deve receber tratamento psicoterápico "encorajando a pessoa a expressar seu pesar e superar suas fixações ou bloqueios para que possa se aperceber do que acontece e daí reaprender o mundo" (Parkes, 1998, p. 226).

Por outro lado, um erro fundamental é "considerar que existe um único tipo de luto patológico e um único tratamento apropriado" (Parkes, 1998, p. 227); por isso é essencial que a família tenha tolerância para com o idoso enlutado e, principalmente, que desenvolva a comunicação e o compartilhamento de sentimentos sobre a perda, buscando contornar a ruptura do equilíbrio familiar. Este ajustamento das condições externas favorece o ajustamento das condições internas e de crenças, permitindo ao idoso seguir em frente ao invés de, inconscientemente, escolher morrer.

Ainda que não valorizado, o luto é um tema a ser resgatado pelo meio acadêmico para que revalidemos sua importância na vida do idoso, principalmente considerando as manifestações físicas e psíquicas que ele favorece, as quais podem ser maiores e mais graves nesta faixa etária.

\section{REFERÊNCIAS}

Ballone, G. J. (s/d). Alterações emocionais do envelhecimento. Recuperado em 18 de março de 2006, de http://gballone.sites.uol.com.br/geriat/envelhecimento.html.

Brasil Escola (s/d). Um estudo teórico da morte. Recuperado em 16 de fevereiro de 2007, de http://www.brasilescola.com/ psicologia/estudo-teorico-morte2.htm.

Goldfarb, D. C. (2002). Psicanálise e envelhecimento. Revista Kairós, 2(ago), 13-18.

Kovács, M. J. (Coord.). (2002). Morte e desenvolvimento humano. São Paulo: Casa do Psicólogo.

Parkes, C. M. (1998). Luto: estudos sobre a perda na vida adulta. São Paulo: Summus.

Rezende, V. L. (Org.). (2000). Reflexões sobre a vida e a morte: abordagem interdisciplinar do paciente terminal. Campinas: Unicamp.

Recebido em 18/08/2006

Aceito em 12/12/2006

Endereço para correspondência: João Batista Alves de Oliveira. Rua Sargento Geraldo Berti, 305, Cep 12280-052, CaçapavaSP.E-mail:drjoao@gmail.com 